\title{
Theoretical Review on Leaping Development of Regional Economies
}

\author{
Liu meiling \\ Guilin University of Electronic Technology \\ Guilin, Guangxi, China \\ 173596553@qq.com
}

\author{
Lu runde \\ Guilin University of Electronic Technology \\ Guilin, Guangxi, China
}

\begin{abstract}
As a mode of economic development, leaping development has attracted close attention from the government, academia and the business community. Based on the origin, concept, condition, mechanism and influencing factors of the leaping development of regional economy, the article collected, collated and commented the relevant literatures. And it puts forward to the evaluation system and development model, organization and mechanism of regional economic leaping development.
\end{abstract}

Keywords-Regional economy; Leaping development; Influence factors; Mechanism

\section{INTRODUCTION}

Spatial economic imbalance exists not only between developed countries and developing countries, but also in developed countries and developing countries, too [1]. In 2016, China's economically developed eastern coastal areas accounted for $13.5 \%$ of China's land, accounting for $42.8 \%$ of China's population produced $59.26 \%$ of China's GDP, while the western region accounted for $72 \%$ of China's land, accounting for $28 \%$ of China's population only produced $20.32 \%$ of China's GDP. This spatial imbalance has also become the core issue in many debates. Economists have long been trying to figure out why the economy will grow, and why some countries are far richer than others. Therefore, regional economics has become one of the economics subjects that can explain the imbalance of space economy. The leap forward development of regional economy is the latest research theory about the imbalance of space economy and how do the backward areas catch up with the developed regions. So far, there are so many general theories about the domestic and foreign general regional economic development (growth), and the research tends to become mature and perfect. However, there are few studies on the theory of the leap forward development of the regional economy abroad, but there are some studies in China, that's not enough. Therefore, the article aims to enrich the theories of the leaping development of regional economy, including the connotation, the conditions and the mechanism, the influencing factors and so on.

\section{THE EXISTING LITERATURE OF REGIONAL ECONOMIC DEVELOPMENT}

\section{A. The origin and connotation of the leaping development of regional economy}

The origin of Regional Economics (Spatial Economics) can be traced back to the traditional classical location theory in Germany. At the end of nineteenth Century, Germany has completed the first industrial revolution, and quickly became the source of one of the second industrial revolution. Due to the rapid development of industry, the problems of industrial migration and industrial layout are paid attention by the scholars. In 1909, Webb wrote The Industrial location Theory. In this masterpiece, Webb systematically established a series of concepts, principles and rules, and described the general location theory rigorously, and developed another school of spatial economics. Since then, the new classical location theory representative Walter Chris teller and Auguste loersch published the Central Region in Southern Germany and Regional Economics respectively in 1933 and 1939. The former puts forward the central local theory, and the latter applies the general equilibrium theory to space research with the most general description. In 1956, Walter integrated the previous model into a unified framework, and created a new field of regional science. Later, Paul Krugman (1979) found a new world of new economic geography, and he thought location theory was part of the economic geography [2]. Around twenty-first Century, the theory of leap forward development of regional economy began to sprout, and at the same time, China's academic circles began to focus on the leap forward development theory, instead of simply studying the "catch up" theory. Based on Yifu Lin's strict econometric test on the data of 36 countries and regions from 1970 to 1992, the catching up strategy which violates the comparative advantage tends to worsen the income distribution. Yifu Lin believes that developing countries must abandon the catch-up strategy. Similarly, Liu Shangxi (2011) opposes the traditional theory that each stage of economic development cannot be crossed, and he believes that the leap forward development is to break through the conventional, break the straight line, and achieve the leaping from a development stage to another new. 
B. Conditions and Mechanism of the Leaping Development of Regional Economy

1) Conditions of leaping development

Li Jianfei (2012), taking Florida of the United States as a reference, studied and analyzed the conditions of the leap forward development of Florida: first, taking the road of differential development based on the advantages of resources; second, establish and improve a diversified industrial system; Third, improve infrastructures and build a developed transportation network, formulate supportive policies on talents, industry, environment and taxation etc.. Wang Xigen, Wu Xiaochuan (2012) put forward the legalization of the leapfrog development, they believe that the leap forward development requires institutional innovation and fresh initiatives taken by the government. The Xinjiang Uygur Autonomous Region finance department research group (2013) pointed out that twothirds of Xinjiang's fiscal expenditure relies on central transfer payment, and the gap between financial security and demand is large, which is not enough to support the leap forward development. Ding Shouqing, Huo Guoqing (2014) hold that the leadership situation and the ability of the follower cannot meet the conditions of the leap forward development in the western minority areas. The leadership of change is necessary.

\section{2) The mechanism of leaping development}

Wang Suse (1985) explains the mechanism that the Arab Nation across the slave society, achieving a leaping from the end of primitive society to the feudal society because of the feudal system factors coming from conquered areas after warfare. David Romer (1986) believes that the social infrastructure is the core basic variables of transnational income gap in the research model when he studied how the second world war affects West Germany, therefore it is the significant and quick change of the social infrastructure that causes the most growth miracles and growth disasters [3]. And Zhang Renfeng, Wang Yingying (2013) points out that the regional collaborative innovation mechanism, that is the enterprises, universities and governments interact and affect together, is the fundamental motive force for the rapid development of regional economy. In addition, Wang Xinliang (2014) analyzes how the spatial development mechanism affects regional economies by studying the time evolution of regional economic differences.

\section{The Influence Factors of The leaping Development of Regional Economies}

\section{1) From the econometric analysis}

Through introducing the variable about human capital, David Romer (1986) found that both the changes of physical capital and human capital can affect the income gap, while the influence of the output of the fixed capital stock is stronger. And it seems that the difference of social infrastructure is the key factor. More importantly, most historical evidence from Hongkong and Taiwan, East Germany and West Germany, South Korea and North Korea shows that social infrastructure has a great impact on income. Gao zhigang (2013) reveals that the reasonable system structure is an important factor in determining the output capacity of the city using city scaleoutput model based on the time series data coming from 19 cities of Xinjiang from 1995 to 2007. Wang Xueding (2012) points out that Gansu should strengthen the economic ties with neighboring provinces and cities by analyzing the central functional strength of 14 cities in Gansu Province. And Xionglang etc. (2013) analyse the absolute convergence of economic growth through the spatial panel data model from 1953 to 2010 . The result shows that the spatial correlation of China's regional development has increased year by year, and it have become an important factor that affects economic growth. In addition, Yao Shujie (2016) introduces the new variableupgrading of industrial structure in the performance evaluation model, using the generalized GMM method and panel data of 9 border provinces from 1993 to 2014. He found that the open border and upgrading of industrial structure have a great influence on economic growth of border provinces.

However, there are some scholars deny the existence of the leap forward development of regional economy through econometric analysis. Zhou Xiaoyan et al. (2016) analyzed the spatial pattern and evolution process of the economic development level of 73 cities in the Yellow River River Basin from 1990 to 2013. The research shows that the economic development of the Yellow River basin has the trend of club convergence and the initial state plays an important role in regional economic development, so the leaping development of regional economic level basically does not exist [4].

\section{2) From the theoretical research}

Gong Xiaoju (2012) research and analysis of factors affecting the regional leap forward development from the perspective of financial policy. It mainly includes undeveloped capital market, imperfect financial system, serious outflow of funds and poor credit environment in underdeveloped areas. Zhou Wen (2013) thinks that the spatial factor is the decisive factor of the regional development of our country, the spatial location is different, the development level is also different obviously. In addition, Zhang Hongli (2012) and Xiao Jinfeng (2015) find that there is mutual promotion relationship between the capital market and economic development by reviewing the economic theory. They point out that the labor, capital and technology play key roles in the unbalanced development of regional economy. And Zhang Renfeng (2013) and Wang Zhuxuan (2014) believe that science and technology innovation is the breakthrough to achieve regional coordinated development and efficient growth.

\section{3) From case analysis}

$\mathrm{Xu}$ Xiaorong (2011) pointed out that the shortage of funds has become a prominent problem of restricting the development of Yunnan province. Jiang Ailing (2013) thinks it is necessary to speed up the transformation of economic development mode in order to realize the great leap forward development of Xinjiang. Gong Xiaoxia (2015) analyzes the factors of restricting the economic development of Gansu Province in ethnic areas, it mainly includes: the weak economic foundation and unreasonable economic structure, the lack of funds for development, the lack of human resources, underdevelopment of science and technology and so on. In addition, Yuan Mingxu (2016) believes that the economic lag and talent shortage in the western region have formed a vicious circle, which involves interaction and cause-and-effect relationship on both sides. To break this cycle, the innovation of talent development scheme is the key breakthrough. 


\section{RESEARCH REVIEW AND FUTURE WORK}

\section{A. Research review}

In the past few decades, the basic research on economic growth and leap forward development has made breakthrough progress, and is still in constant exploration.

\section{1) The origin and connotation}

Regional economic leaping development is the product of a certain stage of regional economic development and the current stage of development is still in its infancy, so the connotation and extension of the theory research is still not perfect. It goes beyond the "catch-up" theory and it is a kind of great leap of economic development stage.

\section{2) Conditions and Mechanism}

The research on the conditions of leaping development is relatively rich, mainly involving resource advantages, industrial system, infrastructure, government system, financial support and so on. While there are few study on the mechanism of leap forward development. There are many perspectives, including war shock, social infrastructure, technological innovation, spatial mechanism, etc., but the systematic and complete theory has not yet been formed.

\section{3) The Influence Factors}

Most of the scholars take the backward relatively western regions as the research object to explain the influence factors. They are mainly include three types: the measurement indexes based on some measurement models or evaluation systems, the determining factors based on some basic theory and mechanisms and the restrict or promote factors based on the analysis of some typical cases.

\section{B. Future work}

Some of the past studies based on accounting, some statistics, and some purely theoretical articles. Scholars have different views on regional economic growth, income disparity and backward areas development. However, due to the short span of the development of regional economy, most studies remain on the surface, and need to be further explored. To sum up, the alternative directions of the future work could be:

\section{1) The definition of concept}

We can expand the concept of leap forward development from the economic, institutional and productivity levels, and give a relatively complete definition, which is conducive to further research.

\section{2) The evaluation system}

Only by knowing the level of regional economic development can we scientifically choose the target and standard. The evaluation system is the basis for measuring the level of regional economic development. With the qualitative analyses exist more and more, scholars may pay attention to how to measure the regional economic development level. At present, some scholars have put forward some evaluation systems, but they cover different ranges. How to establish a more scientific, concise and systematic evaluation system of regional economic development level will become an important research direction.

\section{3) The development model}

Different regional industrial factor endowments are different, and the formation and development process of industrial clusters are also different. We can further study the mechanism and conditions of the leap forward development of regional economy, and then explore the mode, development mode and development path of the leap forward development.

\section{4) The development organization}

It means the distribution situation consisting of each department and each link elements in a certain space, and the configuration and re-configuration process formed of flow, transfer or regroup because all kinds of resources, production factors and companies of all industries choose the best location in the city. Even it means the interactive structure between the same industry and the enterprises in the same market, which determines economies of scale.

\section{5) The development mechanism}

At present, the theory of agglomeration mechanism of macro economy is relatively mature, but the leap forward development of regional economy does not require careful analysis of the internal structure of aggregates. In fact, the characteristics of the interaction within the aggregates imply that this interaction is ignored at the regional level. So far, it is generally believed that regional development depends on the micro elements which are not controlled by the market, which is the basic element that can explain the macroeconomic imbalances. Integrating these elements and exploring their interaction mechanism will help to enrich the theoretical system of leap forward development, and promote the development of economy in backward areas or late developing regions.

\section{CONCLUSION}

Today, the great leap forward development have caught the eyes of all fields of society, but the theoretical research on leaping development is not deep enough and its theory system has not been formed, so it can not provide effective policy guidance for the government, causing that the industry main body have no standard to follow in the process of practice. Therefore, further study on the leapfrog development is needed. Many scholars believe that China has started to enter the post industrialization era, the trend of the times requires us to accelerate the upgrading of industrial structure and the transformation of the mode of production. The leap development is on the time. The domestic and foreign development experiences has confirmed that the leaping development can make the economic growth achieve a qualitative leap, the reason why we choose the leaping development is that the economic development between the Eastern and the Western China is imbalance, the income gap is large, the Western economy needs to develop quickly through leaping development, and then reduce the regional income gap between the East and the West. 


\section{REFERENCES}

[1] Pierre. Philip Coombs, Thierry Meyer and Jacques. Francois Thys, "Economic geography: regional and national integration", Beijing: Renmin University of China press, p.1, 2011.

[2] Liang Qi. "Spatial Economics: past, present and future", Economics Quarterly, vol. 4, pp. 1068-1069, 2005.

[3] David Romer, "Advanced Macroeconomics", Shanghai University of Finance and Economics press,pp. 114-138, 2014.

[4] Zhou Xiaoyan, Hao Huidi, Ye Xinyue, Qin Yawen and Ma Wei, "Spatio temporal dynamic analysis of regional economic disparities in the Yellow River River Basin," Human Geography, vol.5, pp.124-125, 2016 . 